\title{
Absceso Cerebral Secundario a Dilataciones Esofágicas
}

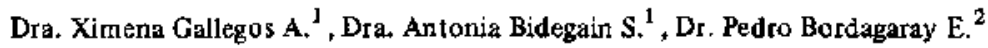

Cerebral Abscess Related to Esophageal Dilatation Procedures.

\begin{abstract}
A case of cerebral abscess due to esophageal dilatations in a boy who had a stenotic lesion of the esophagus after accidental intake of soda is reported.

After three months of periodic dilatations the patient presented fever, vomiting, meningeal and neurologic signs, right sided seizures and a spinal fluid with 4650 leukocy tes per $\mathrm{mm}^{3}$ with normal glucose but elevated proteins levels. Because of aphasia and right hemiparesis studies were carried out which showed a big right frontoparietal cerebral abscess $(25 \mathrm{cc})$. Bacteriology gave positive results to Streptococcus Pneumoniae and Hemophitus Influenzae.

After surgery his evolution was not atisfactory because of residual neurologic damage and persistent esophageal sterosis.
\end{abstract}

La asociación de absceso cerebral y dilataciones esofágicas se ha descrito en contadas ocasiones en la literatura pediátrica ${ }^{3}$ y otorrinolaringológica ${ }^{5}$.

\footnotetext{
1 Pediatra. Hospital Regional de Concepción.

2 Otorrino-laringólogo. Hospital Regional de Concepción.
}

Desconocemos publicaciones nacionales lo que nos ha motivado a presentar un caso especialmente dramático que se presentó en nuestro Servicio en 1981.

\section{CASO CLINICO}

W.O.M. Ficha 837693 . F.N.: 1975

El 20 de Julio de 1981, a los 6 años 6 meses, 
ingiere accidentalmente soda cáustica, como consecuencia desarrolla una estenosis cicatricial de esófago a nivel de la zona cricofaríngea que se trata con dilataciones por vía alta. Los controles radiológicos demuestran un lumen esofágico correspondiente a un quinto de lo normal que dificulta la alimentación por lo que se realiza gastrostomía tipo Witzel (7. Septiembre 1981) e inician dilataciones por vía retrógrada bajo anestesia general. Después de diez dilataciones el esófago está rígido y estenótico en el tercio medio, pero su calibre permite la alimentación oral. (Figura 1).

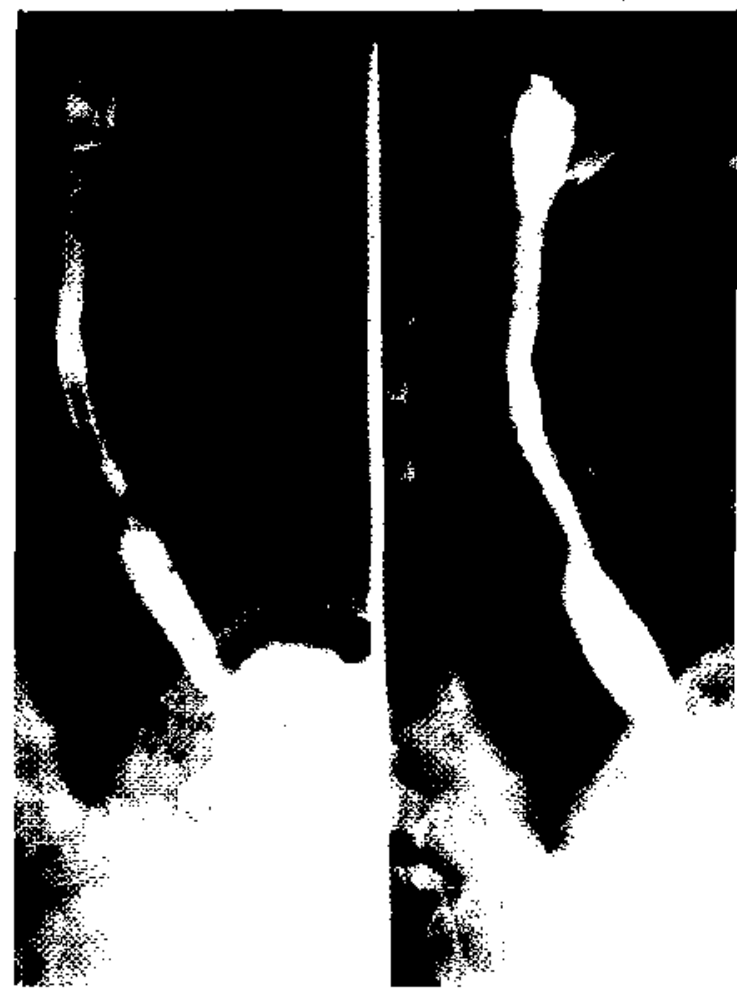

Figura 1.

Entre el 23 de Octubre y 4 de Noviembre cursa con un cuadro bronquial agudo por lo que se suspenden las dilataciones. En la madrugada del 5 de Noviembre presenta fiebre, vómitos, franca desorientación. En la base pulmonar izquierda el residente describe disminución del $M V$ que no se evidencia en sala posteriormente. EI LCR revela 4250 células $\times \mathrm{mm}^{3} 94 \%$ segmentados, proteínas $0.91 \mathrm{~g} \%$ glucosa normal. Horas después se obtienen signos meníngeos, hay irritabilidad, compromiso inicial de conciencia e hipotonía de la extremidad inferior derecha (superior con fleboclisis) con leve desviación de la comisura labial a izquierda. Se inicia tratamiento con Penicilina y Cloramfenicol que se retira al segundo día al llegar un cultivo de LCR negativo coincidente con un aparente aumento de volumen parotídeo. Durante un par de días el niño cursa con somnolencia, desco. nexión con el medio, fiebre, convulsiones tónico clónicas lateralizadas a derecha y se hace más evidente la hemiparesia fasciobraquiocrural derecha. El LCR de control a las 48 horas muestra 50 elementos $/ \mathrm{mm}^{3} 30 \%$ polinucleares, glucosa normal y proteínas $0.73 \mathrm{~g} \%$ El cultivo resulta nuevamente negativo.

Un tercer examen de LCR muestra recuento normal de células con proteinas $0.88 \mathrm{~g} \%$ a mientras se pesquisa afasia motora. Electroencefalograma (EEG): daño extenso profundo en hemisferio izquierdo.

Angiografía carotídea: Extenso proceso expansivo frontoparietal izquierdo.

Tomografía Axial Computada (T.A.C.): absceso cerebral frontoparietal izquierdo. (Figuras 2, 3 y 4).
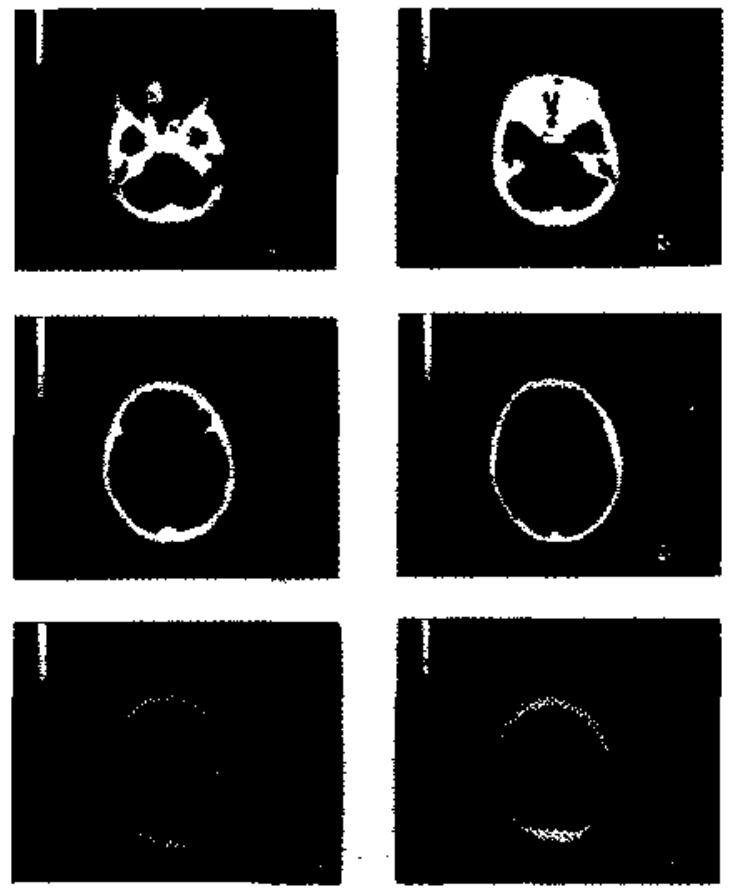

Figura 2.

Intervenido de urgencia por descompensación de su hipertensión endocraneana, se aspira un absceso de $25 \mathrm{cc}$ de pus maloliente que deja una cavidad polilobulada. No es posible cerrar con plaqueta ósea ante la imposibilidad de reducir la masa cerebral. El niño tolera bien la intervención.

El cultivo de pus mostró desarrollo de Hemófilus Influenzae y Streptococo pneumoniae. 

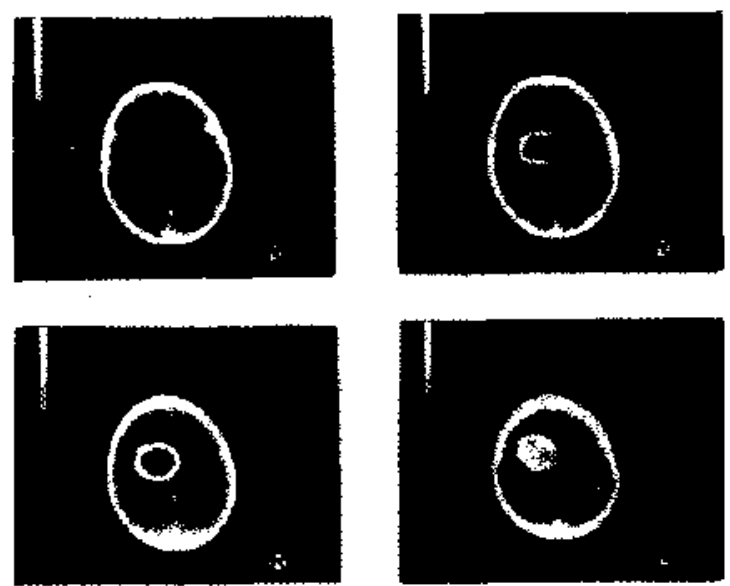

Figura 3.
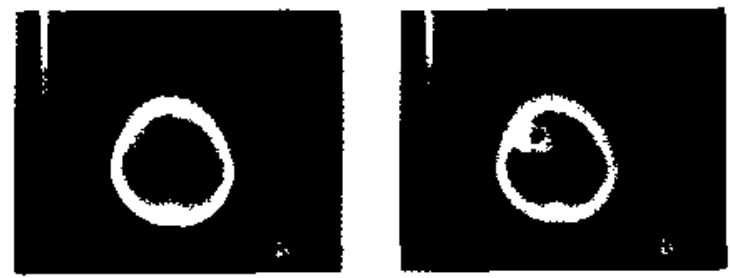

Figura 4.

La recuperación del paciente es lenta con evidente deterioro de sus capacidades intelectuales y agravación de la estenosis esofágica que prolonga su hospitalización hasta Abril de 1982, evolución que escapa al interés de esta presentación.

\section{COMENTARIO}

Los abscesos cerebrales son poco frecuentes en la edad infantil y en una proporción cercana al $90 \%$ son secundarios a focos infecciosos, ya sea contiguos a la masa cerebral en que la propagación se hace por contigüjdad o a travês de trombos vasculare $^{1-2}$ como ocurre en las lesiones de mastoides, oido medio, senos paranasales, infecciones del cuero cabelludo; a distantes de ella, como ocurre en las cardiopatías congénitas cianóticas, endocarditis bacteriana, infecciones broncopulmo. nares, en que la diseminación es hematógena ${ }^{1-2-3}$.

Los abscesos pueden formarse en el tejido cerebral mismo o en los espacios epi-y subdural y en su etiología participan Cocos Gram +, Bacilos Gram - (Hemófilus), algunas Enterobacterias (Citrobacter, Protheus ${ }^{6-7}$, Anaerobios ${ }^{4-\theta}$ e incluso Hongos y Parásitos. Además, pueden encontrarse asociaciones de gérmenes ${ }^{3}$ como en el caso presentado.

Las dilataciones esofágicas, causa poco común de abceso cerebral, provocarían microperforaciones del esófago que al infectarse pennitirian paso de gérmenes al mediastino (mediastinitis) y diseminación hematógena que llevaría los agentes infecciosos al tejido encefálico. ${ }^{3}$. En nuestro paciente se descartan las causas habituales de abscesos, siendo el episodio bronquial de escasa magnitud y curso afebril. Dado el claro antecedente de dilataciones atribuimos a ellas el cuadro clínico. Sin desconocer la posibilidad de que las mismas lesiones esofágicas pudieran haber causado una mediastinitis en forma primaria, los autores consideran que el largo tiempo transcurrido (3 meses) resta valor a esta explicación.

Es de interés destacar esta patologia para que la vigilancia de estos pacientes permita detectar la complicación a tiempo y evite o reduzca el daño neurológico, lo que no ocurrió en el niffo presen. tado.

\section{REFERENCIA}

1 Meneghello, Tomo II, 1972. Edit. Intermédica,

${ }^{2}$ Nelson, Tomo II, 1971 . Edit. Salvat.

${ }^{3}$ Leahy, W.R. et al.: Cerebral Abscess in children secondary to esophageal dilatations. Ped. Vol. 59, No 2 . Feb. 77.

4 Brook, ltzhok.: Bacteriology of intracranial abscess in children. J. Neurosurg. 54: 484-488, 1981.

5 Rontal, $E_{\text {. }}$ et al.: Metastatic abscess as a complication of retrograde esophageal dilatation. Ann. Otol. Rin. Laryng. 82;643,73.

6 Grahom, D, ei al.: Citrobader diversus brain abscess and meningitis in neonates. Jama, Mayo 15, 1981. Vol. 245.

${ }^{7}$ Smith, M,L., Mellor, D.: Psotheus mirabilis meningitis and cerebral abscess in newborn period. Arch. Dis. Childhood. Vol. $55 \mathrm{~N}^{\circ} 4$, Abtil 80.

Beeden, Gordon, Willis, Trewor.: A case of anaerobic middle ear infection with complications. Journal of Laryagology, Otology. June 1980, Vol. 94. 